\title{
Evaluation of the accuracy of the Leap Motion controller for measurements of grip aperture
}

\author{
Rebecca L. Hornsey \\ Department of Psychology \\ University of Essex \\ Wivenhoe Park \\ Colchester, CO4 3SQ, UK \\ rhorns@essex.ac.uk
}

\author{
Paul B. Hibbard \\ Department of Psychology \\ University of Essex \\ Wivenhoe Park \\ Colchester, CO4 3SQ, UK \\ phibbard@essex.ac.uk
}

\section{CCS Concepts}

•Human-centered computing $\rightarrow$ Laboratory experiments; •Hardware $\rightarrow$ Sensors and actuators;

The Leap Motion controller allows for a mouse-free alternative to general computing. With 200 frames/second infrared cameras, a $150^{\circ}$ field of view and an $8 \mathrm{ft}^{2}$ umbrella of interactive space, the Leap Motion has many potential practical applications. The device is advertised as aiming to be placed in new cars, laptops and hospitals, for example, to provide contact-free device control, while reducing the need for attentive button pressing and averting eye focus.

We assessed the accuracy of the Leap Motion when the correct hand position is known. Other studies have also assessed the accuracy of the device, tracking either a reference pen manipulated by a robot arm [1], or the positions of participant's fingers while pointing at a computer screen [2]. We assessed the accuracy with which grip aperture (the separation between the thumb and forefinger) can be measured. This gesture is useful for indicating the size of objects, or the separation between points. Thirteen wooden rods were created in centimetre increments between 1 and $13 \mathrm{~cm}$. These were held by participants between their thumb and forefinger tips above the Leap Motion, before removing them, but keeping the hand position stable (Figure 1a). Ten trials were completed before checking the size with the rod and repeating for another 10 , giving 20 repeats for each size. The endpoints of the participant's fingers were recorded from the Leap Motion using MATLAB and Matleap [3], and the Euclidean distance between the endpoints was calculated.

A linear regression was performed on the median separation as measured by Leap Motion, against the actual grip aperture. This accounted for between 94.8 and $98.4 \%$ of the variance, across participants. Each participant's regression equation was used to calculate a grip aperture estimate from the Leap Motion data on each trial. The mean, median and RMS error, for each grip aperture, were then calculated for each participant (Figure 1b). The mean RMS was greatest

Permission to make digital or hard copies of part or all of this work for personal or classroom use is granted without fee provided that copies are not made or distributed for profit or commercial advantage and that copies bear this notice and the full citation on the first page. Copyrights for third-party components of this work must be honored. For all other uses, contact the owner/author(s).

CVMP 2015 November 24-25, 2015, London, United Kingdom

(C) 2015 Copyright held by the owner/author(s).

ACM ISBN 978-1-4503-3560-7/15/11.

DOI: http://dx.doi.org/10.1145/2824840.2824855
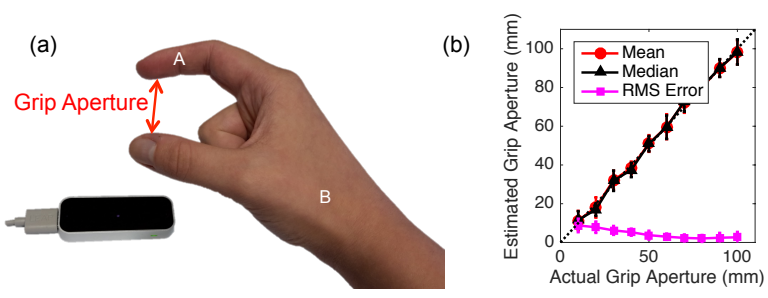

Figure 1: (a) Leap Motion was used to measure the grip aperture. This figure shows (A) the interphalangeal joint and (B) the cleft below the trapezoid. (b) The mean, median and RMS error of the estimated grip apertures. Data points plot the mean across 7 participants, error bars show \pm 1 standard deviation.

for small grip apertures $(8.78 \mathrm{~mm}$ at $10 \mathrm{~mm})$ and reduced with increasing grip aperture $(2.67 \mathrm{~mm}$ at $100 \mathrm{~mm})$. The mean RMS error was $4.44 \mathrm{~mm}$; for grip apertures larger than $50 \mathrm{~mm}$, mean RMS errors were always smaller than $4 \mathrm{~mm}$.

A bend in the inter-phalangeal joint was necessary for reliable measures. Measurements were taken from the cleft below the trapezoid to the tip of the straightened forefinger and thumb for each participant (Figure 1a). The square root of the sum of these lengths squared was then calculated. Only participants for whom this length was over $19 \mathrm{~cm}$ could be tracked accurately for grip apertures greater than $10 \mathrm{~cm}$.

Acknowledgements: This work was supported by the British Academy and the University of Essex Undergraduate Research Opportunities Programme.

\section{REFERENCES}

[1] F. Weichert, D Bachmann, B. Rudak and D. Fisseler. Analysis of the accuracy and robustness of the Leap Motion controller. Sensors 13:6380-6393, 2013.

[2] J.Y.Tung, T. Lulic, D.A. Gonzalez, J. Tran, C.R. Dickerson and E.A. Roy. Evaluation of a portable markerless finger position capture device: accuracy of the Leap Motion controller in healthy adults. Physiological Measurement 36(2015):1025-1035, 2015.

[3] https://github.com/jeffsp/matleap.git 